\title{
Who goes to sexually transmitted disease clinics? Results from a national population survey
}

\author{
A M Johnson, J Wadsworth, K Wellings, J Field
}

Objectives: To examine the pattern of attendance at sexually transmitted disease (STD) clinics in Britain. To compare the demographic characteristics, behaviours and attitudes of STD clinic attenders with those of non-attenders, and to assess the extent to which STD clinics are used by those with high-risk sexual lifestyles.

Design: Random sample general population survey of sexual attitudes and lifestyle.

Subjects: 18,876 randomly selected men and women resident in Britain aged 16-59 years.

Main outcome measures: Demographic characteristics, pattern of homosexual partnerships, heterosexual partnerships, payment for sex, abortion, drug injection in the last five years, and attitudes to sexual behaviours amongst 512 respondents who had attended STD clinic in the last five years compared with those who had not.

Results: $8 \cdot 3 \%$ of men and $5 \cdot 6 \%$ of women had attended a clinic in their lifetime and $3 \cdot 4 \%$ and $2.6 \%$ respectively in the last five years. Attendance rates varied substantially with area of residence. $11 \%$ of Inner London residents had attended in the last five years. In multivariate analysis, STD clinic attendance for men was most strongly associated with increased numbers of heterosexual partners, $(O R=6.01(4 \cdot 44-8 \cdot 15))$ and homosexual partnerships $(O R=9.59$ $(5 \cdot 83-15 \cdot 8))$ and more weakly associated with payment for sex, non-manual social class, age 25-44, unmarried status and smoking. Clinic attendance for women was most strongly associated with numbers of heterosexual partners $(O R=3.74(2 \cdot 76-5 \cdot 08)$ ) and injecting drug use $(O R=$ $4.39(1 \cdot 73-11 \cdot 1))$. A weaker independent association was found with a history of abortion, anal sex, non-manual social class, non-married status and age 16-24. From the total population, 1 in 6 men and 1 in 7 women in the top $5 \%$ of the distribution for numbers of heterosexual partners and 1 in 5 men paying for sex and 1 in 4 of those with a homosexual partner had attended a clinic in the last five years. The probability of attendance increased with multiple risk behaviours. Of women $64.2 \%$ and of men $69 \cdot 7 \%$ attending clinics reported major risk markers for STD transmission.

Conclusions: STD clinics in Britain are used by a wide demographic spectrum of the population. The behaviours, but not the attitudes, of attenders differed markedly from those of non-attenders. Clinics are relatively efficient in attracting only those with high-risk lifestyles, but, at a population level, the minority of those reporting risk-markers for STD transmission attend clinics. These findings suggest that STD clinics are an important focus for sexual health promotion, but that community programmes are also important for reaching non-attenders.

(Genitourin Med 1996;72:197-202)

Keywords: STD; clinics; attenders

Department of Sexually Transmitted Diseases, University College London Medical School, London WC1E 6AU

$M$ Johnson

Academic Department of Public Health, St

Mary's Hospital

Medical School,

London W2 1PG

J Wadsworth

Department of Public

Health and Policy,

London School of

Hygiene \& Tropical

Medicine, London

WC1E 7HT

$\mathrm{K}$ Wellings

Social \& Community

Planning Research,

London ECIV OAX

$\mathrm{J}$ Field

Address correspondence to:

Dr A M Johnson.

Accepted for publication

14 February 1996

\section{Introduction}

Britain is one of the few countries worldwide to have a comprehensive open-access national network of genitourinary medicine (GUM) clinics for the free treatment of sexually transmitted diseases. Available evidence suggests that the majority of diagnosed sexually transmitted diseases (STDs) are treated in these clinics, which contrasts with the situation in the United States and other countries where a substantial proportion of disease is treated in private clinics and by primary care physicians. ${ }^{1}$

Statistics from GUM clinics record cases rather than persons, and since one individual may have several diagnoses, direct estimates of the numbers of people attending are unavailable. ${ }^{2}$ Knowledge of the demographic and behavioural characteristics of attenders from routine statistics collated by the Department of Health (KC60) is limited to age, sex and location of treatment. ${ }^{3}$ In recent years, the importance of STD control has been highlighted by the HIV epidemic. GUM clinics remain the focus for both HIV and STD management. HIV and sexual health have been designated key areas in the government White Paper Health of the Nation and targets have been set for reduction in gonorrhoea incidence. ${ }^{4}$ Increased emphasis is being placed on targetting health promotion in clinical settings. This may be particularly appropriate for sexually acquired infections. Risk is not evenly distributed in the population and those with multiple homosexual or heterosexual partners are at greater risk of STD and HIV infection. There is considerable diversity of sexual lifestyle ${ }^{56}$ such that a relatively small proportion of the population at any one time is at high risk of STD acquisition.

GUM clinics offer an important venue for STD control and health promotion, though a high proportion of attenders seen at clinics are found to be free of STD on screening ${ }^{1}$ and clinics may be used for conditions such as candidiasis which are not always sexually transmitted as well as for routine cervical cytology. 
Table 1 STD clinic attendance in the last five years by geographical region

\begin{tabular}{llllll}
\hline & \multicolumn{2}{l}{ Men } & & \multicolumn{2}{l}{ Women } \\
\cline { 2 - 3 } \cline { 5 - 6 } & $n$ attending/base & $(\%)$ & & $n$ attending/base & $(\%)$ \\
\hline Inner London & $43 / 399$ & $(10 \cdot 9)$ & & $59 / 521$ & $(11 \cdot 3)$ \\
Outer London & $31 / 602$ & $(5 \cdot 1)$ & & $20 / 646$ & $(3 \cdot 1)$ \\
$\begin{array}{l}\text { Other Metropolitan } \\
\quad \text { Cities }\end{array}$ & $58 / 1751$ & $(3 \cdot 3)$ & & $58 / 2347$ & $(2 \cdot 5)$ \\
Elsewhere & $130 / 4880$ & $(2 \cdot 7)$ & & $114 / 6070$ & $(1 \cdot 9)$ \\
All & $262 / 7632$ & $(3 \cdot 4)$ & & $250 / 9584$ & $(2 \cdot 6)$ \\
\hline
\end{tabular}

Relatively little is known about the pattern of use of STD clinics. Surveys of sexual behaviour in clinic populations have in general been limited to single clinics and have no population comparison group. ${ }^{7}$ In this paper, using data from a large random sample, general population survey of sexual attitudes and lifestyle, we examine three questions. Firstly, what proportion of the population in Britain use STD clinics? Secondly, how do clinic users differ from non-users with respect to their demographic characteristics, behaviour and attitudes? Thirdly, what proportion of those with high-risk lifestyles attend clinics?

\section{Methods}

The national survey of sexual attitudes and lifestyles was undertaken in 1990 and 1991. The methodology has been described in detail elsewhere. ${ }^{589}$ In brief, a random sample of 18,876 men and women living in Britain and aged 16-59 years was interviewed in their homes between May 1990 and November 1991. The response rate was $65 \%$ and the sample was broadly representative of the age, marital status and social class structure of the population. The enquiry included demographic, educational and attitudinal questions as well as detailed questions on sexual behaviour. The most intimate questions about sexual behaviour were contained in a selfcompletion booklet completed by the respondent at the time of the interview, but which was not seen by the interviewer. The booklet included a question: "Have you ever attended a sexually transmitted disease (STD) clinic, or special (VD) clinic?" and a question on the time of most recent attendance.

In this paper, we compare the characteristics of all those who reported attending an STD clinic in the last five years with those who had not. We examined demographic characteristics including area of residence, age, marital status, and social class. Sexual behaviours examined include number of heterosexual partners; experience of homosexual partnership; female commercial sex partners; anal sex; and condom use. Heterosexual partners were defined as partners of the opposite sex with whom the respondent had had vaginal, oral or anal sex. Homosexual partners were defined as partners of the same sex with whom the respondent had any kind of genital contact. Finally, other health-related behaviours and attitudes to sexual behaviour were examined. The data were weighted for household size and variability in response between regions as previously described.59 Demographic and behavioural variables were included in stepwise multiple logistic regression models of STD clinic attendance and the results are expressed as adjusted odds ratios with their 95\% confidence intervals.

Factors strongly associated with the probability of STD transmission were combined to assess both the proportion of STD clinic attenders who reported high-risk lifestyles and the extent to which those with high-risk lifestyles attend clinics.

\section{Results}

Of men $0.9 \%$ and of women $0.8 \%$ reported attending an STD clinic in the last year. This rose to $3 \cdot 4 \%$ and $2 \cdot 6 \%$ respectively for attendance in the last five years. Of men $8.3 \%$ and of women $5.6 \%$ had attended a clinic in their lifetime (so far). There was wide variation by age group and lifetime attendance was most widespread amongst $25-34$ year olds $(11 \cdot 8 \%$ of men, $8 \cdot 1 \%$ of women). All further calculations are based on reported attendance in the last five years.

Table 1 shows that attendance rates varied considerably with area of residence. Eleven per cent of men and women resident in Inner London reported STD clinic attendance in the last five years compared with less than $3 \%$ of persons living in areas outside greater London. Attenders were younger, less likely to be married than non-attenders (table 2) and women attenders were more likely to have a non-manual occupation.

The sexual behaviour of STD clinic attenders was strikingly different from that of nonattenders (table 2). Both male and female attenders reported a much higher mean number of heterosexual partners than non-attenders. Since the value of the mean is strongly influenced by a very small proportion of respondents with very large numbers of partners, ${ }^{8}$ we also compared the proportions of respondents who were in the top $5 \%$ or top $15 \%$ of the distribution for reported numbers of heterosexual partners in the last five years. Attenders were nearly eight times more likely than non-attenders to be in the top $5 \%$ or the top $15 \%$ of the distribution. Of male attenders $12 \cdot 1 \%$ reported at least one homosexual partner in the last five years compared with only $1 \cdot 2 \%$ of non-attenders, but female attenders were not significantly more likely to have had homosexual partners. Attenders were more likely to have experience of anal intercourse and to have experience of first intercourse before the age of 16 years. Of male clinic attenders $10 \cdot 3 \%$ had paid for sex with a woman within the past five years compared with only $1.6 \%$ of non-attenders. Clinic attenders were marginally more likely to have used a condom at last heterosexual intercourse, though overall only one quarter had done so.

Female clinic attenders were much more likely to have had an abortion in the last five years $(17 \cdot 8 \%$ compared with $4 \cdot 3 \%)$. Male and female attenders were more likely to report having had an HIV test than non-attenders. Attenders were more than 10 times more likely 
Table 2 Characteristics of those attending STD clinics in last five years compared with those not attending

\begin{tabular}{|c|c|c|c|c|c|}
\hline & & \multicolumn{4}{|l|}{$n$} \\
\hline & & Respondents & Attenders & Non-attenders & Odds Ratio (95\% CI) \\
\hline Age (mean years) $(\mathrm{SD})$ & $\mathbf{M}$ & 7632 & $30 \cdot 0(8 \cdot 2)$ & $36 \cdot 0(12 \cdot 0)$ & - \\
\hline \multirow{2}{*}{ Married (\%) } & $M$ & $\begin{array}{l}9584 \\
7630\end{array}$ & $\begin{array}{l}29 \cdot 0(8 \cdot 1) \\
26 \cdot 0\end{array}$ & $\begin{array}{l}36 \cdot 1(11 \cdot 3) \\
60 \cdot 5\end{array}$ & $0.23(0.17-0.30)$ \\
\hline & $\mathrm{F}$ & 9582 & $26 \cdot 4$ & $63 \cdot 1$ & $0.20(0.15-0.26)$ \\
\hline \multirow[t]{2}{*}{ Social Class Non-Manual (\%) } & $\mathbf{M}$ & 7626 & $57 \cdot 7$ & $55 \cdot 7$ & $1.08(0.85-1.39)$ \\
\hline & $\mathbf{F}$ & 9579 & $66 \cdot 1$ & $59 \cdot 4$ & $1.33(1.02-1.73)$ \\
\hline \multirow{2}{*}{$\begin{array}{l}\text { Mean } n \text { heterosexual partners } \\
\text { last five years }(\mathrm{SD})\end{array}$} & & & & & \\
\hline & $\mathrm{M}$ & 9568 & $\begin{array}{l}8 \cdot 4(11 \cdot 7) \\
3 \cdot 6(3 \cdot 6)\end{array}$ & $\begin{array}{l}2.5(5 \cdot 8) \\
1.5(2 \cdot 1)\end{array}$ & 二 \\
\hline \multicolumn{2}{|l|}{ Top $5 \%$ of distribution for } & & & & \\
\hline $\begin{array}{l}\text { heterosexual partners in } \\
\text { last five years }(M=10+\text {, } \\
F=5+)(\%)\end{array}$ & $\begin{array}{l}\mathrm{M} \\
\mathrm{F}\end{array}$ & $\begin{array}{l}7618 \\
9568\end{array}$ & $\begin{array}{l}25 \cdot 2 \\
27 \cdot 2\end{array}$ & $\begin{array}{l}4 \cdot 3 \\
4 \cdot 1\end{array}$ & $\begin{array}{l}7 \cdot 54(5 \cdot 58-10 \cdot 2) \\
8 \cdot 86(6 \cdot 58-11 \cdot 9)\end{array}$ \\
\hline \multicolumn{6}{|l|}{ Top $15 \%$ of distribution of } \\
\hline $\begin{array}{l}\text { heterosexual partners in last five years } \\
(M=5+, F=3+)(\%)\end{array}$ & $\mathrm{M}$ & 7618 & $53 \cdot 2$ & $11 \cdot 9$ & $8 \cdot 41(6 \cdot 53-10 \cdot 8)$ \\
\hline \multirow{2}{*}{ Homosexual partners last five years (\%) } & M & $\begin{array}{l}9308 \\
7623\end{array}$ & $\begin{array}{l}51 \cdot 8 \\
12 \cdot 1\end{array}$ & $\begin{array}{r}12 \cdot 0 \\
1 \cdot 2\end{array}$ & $\begin{array}{r}7 \cdot 80(6 \cdot 04-10 \cdot 1) \\
11 \cdot 30(7 \cdot 33-17 \cdot 3)\end{array}$ \\
\hline & $\mathrm{F}$ & 9583 & 1.6 & 0.7 & $2.47(0.89-6.85)$ \\
\hline \multirow{2}{*}{$\begin{array}{l}1 \text { st heterosexual intercourse } \\
<16 \text { years }(\%)\end{array}$} & $\mathbf{M}$ & 7565 & $28 \cdot 8$ & $19 \cdot 3$ & $1.68(1.28-2 \cdot 21)$ \\
\hline & $\mathbf{F}$ & 9537 & $23 \cdot 1$ & $8 \cdot 0$ & $3.49(2 \cdot 58-4 \cdot 73)$ \\
\hline $\begin{array}{l}\text { Paid for sex with female partner } \\
\text { last five years }(\%)\end{array}$ & $\mathbf{M}$ & 7563 & $10 \cdot 3$ & $1 \cdot 6$ & $7 \cdot 12(4 \cdot 59-11 \cdot 0)$ \\
\hline Anal sex in last five years (\%) & $\begin{array}{l}\mathrm{M} \\
\mathrm{F}\end{array}$ & $\begin{array}{l}7422 \\
9274\end{array}$ & $\begin{array}{l}21 \cdot 1 \\
20 \cdot 8\end{array}$ & $\begin{array}{l}9 \cdot 8 \\
8 \cdot 9\end{array}$ & $\begin{array}{l}2.48(1.82-3.38) \\
2.69(1.96-3.69)\end{array}$ \\
\hline \multirow{2}{*}{$\begin{array}{l}\text { Condom use last heterosexual } \\
\text { intercourse (\%) }\end{array}$} & $\mathbf{M}$ & 7294 & $27 \cdot 1$ & $23 \cdot 2$ & $1.23(0.91-1.66)$ \\
\hline & $\mathbf{F}$ & 9196 & $23 \cdot 1$ & $17 \cdot 4$ & $1.43(1.04-1.94)$ \\
\hline \multirow{3}{*}{$\begin{array}{l}\text { Abortion last five years (\%) } \\
\text { HIV test for any reason (\%) }\end{array}$} & F & 9404 & $17 \cdot 8$ & $4 \cdot 3$ & $4 \cdot 84(3 \cdot 44-6 \cdot 80)$ \\
\hline & $\mathbf{M}$ & 7528 & $43 \cdot 5$ & $12 \cdot 0$ & $5 \cdot 69(4 \cdot 40-7 \cdot 34)$ \\
\hline & $\mathbf{F}$ & 9419 & $36 \cdot 4$ & $13 \cdot 0$ & $3.83(2.93-4.99)$ \\
\hline \multirow[t]{2}{*}{ ^HIV test for "other" reason (\%) } & $\mathbf{M}$ & 7505 & $31 \cdot 8$ & $3 \cdot 3$ & $13 \cdot 70(10 \cdot 2-18 \cdot 30)$ \\
\hline & $\mathbf{F}$ & 9382 & $18 \cdot 7$ & $2 \cdot 5$ & $9 \cdot 16(6 \cdot 47-13 \cdot 0)$ \\
\hline \multirow[t]{2}{*}{ Current smokers (\%) } & $M$ & 7632 & $55 \cdot 3$ & $38 \cdot 7$ & $1.97(1.53-2 \cdot 52)$ \\
\hline & $F$ & 9584 & $48 \cdot 9$ & $38 \cdot 3$ & $1.53(1.19-1.97)$ \\
\hline \multirow[t]{2}{*}{ Moderate/high alcohol consumption (\%) } & $M$ & 7620 & $24 \cdot 4$ & $17 \cdot 7$ & $1 \cdot 50(1 \cdot 12-2 \cdot 00)$ \\
\hline & $\mathrm{F}$ & 9567 & $10 \cdot 4$ & $9 \cdot 7$ & $1.08(0.72-1.64)$ \\
\hline \multirow[t]{2}{*}{ Injecting drug use last five years (\%) } & $\mathbf{M}$ & 7566 & $2 \cdot 2$ & $0 \cdot 4$ & $6 \cdot 34(2 \cdot 33-16 \cdot 30)$ \\
\hline & $\mathbf{F}$ & 9501 & $2 \cdot 9$ & $0 \cdot 2$ & $15 \cdot 65(5 \cdot 83-40 \cdot 43)$ \\
\hline
\end{tabular}

*For reason other than blood donation, travel, insurance or antenatal screening.

than non-attenders to have been tested for a reason other than blood donation, travel, insurance or antenatal testing, which we interpret as including all those actively seeking an HIV test.

Other indicators of risk behaviour were examined. Attenders were more likely to be current smokers, and male attenders more likely to consume moderate or high amounts of alcohol than non-attenders, but the magnitude of these differences was small compared with those for sexual behaviour variables. Attenders were much more likely to have a history of injecting drug use than non-attenders.

Table 3 Adjusted odds ratios (with 95\% confidence intervals) for STD clinic attendance in the last five years

\begin{tabular}{lll}
\hline & $O R$ & $95 \% C I$ \\
\hline Men & & \\
Age (years) & & \\
$25-34$ & $2 \cdot 09$ & $1 \cdot 55-2 \cdot 84$ \\
$\quad 35-44$ & $1 \cdot 63$ & $1 \cdot 10-2 \cdot 42$ \\
Marital status & & \\
$\quad$ cohabiting & $2 \cdot 05$ & $1 \cdot 31-3 \cdot 19$ \\
$\quad$ widowed/separated/divorced & $2 \cdot 20$ & $1 \cdot 28-3 \cdot 78$ \\
single & $2 \cdot 49$ & $1 \cdot 72-3 \cdot 59$ \\
Non-manual social class & $1 \cdot 61$ & $1 \cdot 20-2 \cdot 15$ \\
Smoker & $1 \cdot 48$ & $1 \cdot 12-1 \cdot 48$ \\
1+ male partner in the last five years & $9 \cdot 59$ & $5 \cdot 83-15 \cdot 8$ \\
$5+$ female partners in the last five years & $6 \cdot 01$ & $4 \cdot 44-8 \cdot 15$ \\
Paid for sex in the last five years & $2 \cdot 06$ & $1 \cdot 23-3 \cdot 45$ \\
Women & & \\
Age (years) & & \\
$\quad$ 25-24 & $1 \cdot 97$ & $1 \cdot 24-3 \cdot 12$ \\
Marital status & $3 \cdot 10$ & $2 \cdot 12-4 \cdot 54$ \\
$\quad$ cohabiting & & \\
widowed/separated/divorced & & $1 \cdot 89-4 \cdot 39$ \\
single & $2 \cdot 88$ & $2 \cdot 07-5 \cdot 09$ \\
Non-manual social class & $3 \cdot 25$ & $1 \cdot 51-3 \cdot 36$ \\
Moderate/heavy alcohol consumption & $2 \cdot 25$ & $1 \cdot 24-2 \cdot 21$ \\
Injected drugs in the last five years & $1 \cdot 66$ & $0 \cdot 387-0 \cdot 925$ \\
3+ male partners in the last five years & $0 \cdot 599$ & $1 \cdot 73-11 \cdot 1$ \\
Abortion in the last five years & $4 \cdot 39$ & $2 \cdot 76-5 \cdot 08$ \\
Anal sex in the last five years & $3 \cdot 74$ & $1 \cdot 33-2 \cdot 84$ \\
\hline
\end{tabular}

\section{Multivariate analysis}

Since many of the demographic variables associated with STD clinic attendance are also associated with sexual behaviour patterns, ${ }^{5}$ a stepwise multiple logistic regression model was used to assess the independent effects of these variables. Variables which remained significantly associated with attendance are expressed in table 3 as adjusted odds ratios with their $95 \%$ confidence intervals.

Age, marital status, social class, region of residence, smoking and alcohol consumption were included for men and women. For men, sexual behaviour variables included in the model were: five or more female partners, one or more male partners, paying for sex, anal sex and injecting drug use in the last five years. For women, the variables were: three or more male partners, abortion, anal sex and drug injecting in the last five years.

For men, clinic attendance remained most strongly associated with numbers of heterosexual partners and male sex partnership and more weakly associated with payment for sex, unmarried status, non-manual social class, age 25-44, and smoking. For women, numbers of heterosexual partners and injecting drug use remained strongly associated with STD clinic attendance and a weaker independent association was found with a history of abortion in the last five years, non-manual social class, nonmarried status, anal sex and age 16-34. No association with region of residence was found after controlling for other variables in the models.

While odds ratios give a measure of the increased probability of high-risk behaviours amongst STD clinic attenders, they give no 
Table 4 Percentage of individuals with risk markers attending STD clinic in last five years

\begin{tabular}{lll}
\hline Risk marker & Base & $\begin{array}{l}\text { Percentage attending } \\
(95 \% \text { CI })\end{array}$ \\
\hline Top 5\% of distribution for heterosexual & M 382 & $17 \cdot 2(13 \cdot 4-21 \cdot 0)$ \\
partners in last five years & F 445 & $15 \cdot 3(11 \cdot 9-18 \cdot 6)$ \\
Top 15\% of distribution for heterosexual & M 1016 & $13 \cdot 7(11 \cdot 6-15 \cdot 8)$ \\
partners in last five years & F 1249 & $10 \cdot 4(8 \cdot 7-12 \cdot 0)$ \\
Homosexual partners last five years & M 118 & $26 \cdot 7(18 \cdot 7-34 \cdot 6)$ \\
Paid for sex with female partner last five years & F 65 & $6 \cdot 3(0 \cdot 37-12 \cdot 2)$ \\
Anal sex last five years & M 143 & $18 \cdot 7(12 \cdot 3-25 \cdot 1)$ \\
Abortion last five years & F 856 & $7 \cdot 2(5 \cdot 4-9 \cdot 0)$ \\
Injecting drug use last five years & F 436 & $5 \cdot 9(4 \cdot 3-7 \cdot 5)$ \\
& M 33 & $10 \cdot 1(7 \cdot 3-13 \cdot 0)$ \\
Any of above risks & F 24 & $17 \cdot 8(4 \cdot 7-30 \cdot 9)$ \\
All respondents & M 1703 & $29 \cdot 5(11 \cdot 4-47 \cdot 7)$ \\
& F 2126 & $10 \cdot 7(9 \cdot 3-12 \cdot 2)$ \\
& M 7632 & $7 \cdot 6(6 \cdot 4-8 \cdot 7)$ \\
& F 9584 & $2 \cdot 4(3 \cdot 0-3 \cdot 8)$ \\
\hline
\end{tabular}
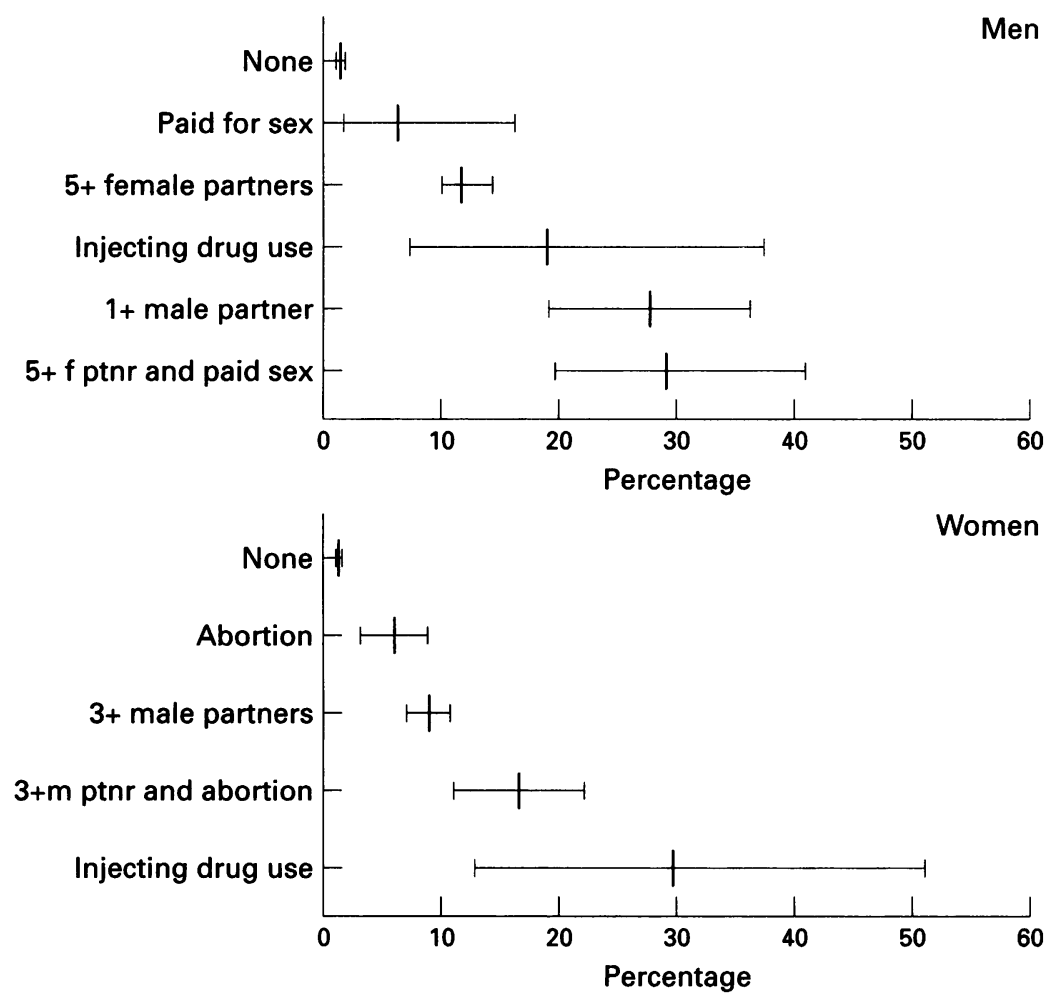

Proportion of respondents with various risk markers attending STD clinics (95\% CI shown by bars). measure of the proportion of those with particular risk behaviours who use these services. This is shown in table 4. Most striking is the relationship with numbers of partners, male homosexual partnership, payment for sex and injecting drug use. One in 6 men in the top $5 \%$ of the distribution for numbers of heterosexual partners; nearly 1 in 5 of those paying for sex, and 1 in 4 of those with a homosexual partner had attended a clinic in the last five years. Among women, around 1 in 7 of those in the top $5 \%$ of the distribution for heterosexual partners had attended a clinic; and nearly $30 \%$ of those with a history of injecting drug use. These figures must be compared with only $3 \%$, or 1 in 33 , of the general population attending in a five-year period. The probability of attending increased with multiple risks (fig) so that, for example, amongst men who were in the top $15 \%$ of the distribution for heterosexual partners who had also paid for sex, the probability of attendance rose to $28 \%$. While among those with no risk markers, only $1 \%$ had attended.

Conversely, in order to examine the extent to which STD clinics are appropriately used by those with high-risk lifestyles, we estimated the proportions of clinic attenders who reported one more of the major risk markers, selecting those characteristics most strongly associated with probability of attendance (top $15 \%$ for heterosexual partners, anal sex, injected drugs, abortion (for women) and $1+$ male partner or paid for sex (for men)). Overall, $64 \cdot 2 \%$ of women attending STD clinics and $69.7 \%$ of men reported one or more of these risk markers. Only $21 \%$ of the nonattenders reported one or more risk markers. Because the non-attenders account for the majority of the population, however, these individuals out-number by a factor of $8: 1$ in men and 12:1 in women the individuals with risk markers attending STD clinic.

Attitudes

Since attitudes are believed to be related to behaviour patterns, we compared attitudes of attenders with those of non-attenders concerning their views on sexual behaviour. These are

Table 5 Comparison between attitudes of attenders at STD clinics in last five years with those of non-attenders

\begin{tabular}{|c|c|c|c|c|c|c|}
\hline & & \multicolumn{2}{|c|}{ Attenders } & \multicolumn{2}{|c|}{ Non-attenders } & \multirow[b]{2}{*}{ Significance $^{\star}$} \\
\hline & & $\%$ & Base & $\%$ & Base & \\
\hline $\begin{array}{l}\text { Proportion describing themselves as } \\
\text { "not at all at risk from AIDS" } \\
\text { Attitudes to sexual behaviour } \\
\text { Proportions reporting that behaviours } \\
\text { are rarely wrong or not wrong at all (\%) }\end{array}$ & $\begin{array}{l}\mathrm{M} \\
\mathrm{F}\end{array}$ & $\begin{array}{l}43 \cdot 7 \\
51 \cdot 3\end{array}$ & $\begin{array}{l}261 \\
250\end{array}$ & $\begin{array}{l}74 \cdot 2 \\
79 \cdot 4\end{array}$ & $\begin{array}{l}7343 \\
9300\end{array}$ & $\begin{array}{l}\mathrm{p}<0.001 \\
\mathrm{p}<0.001\end{array}$ \\
\hline $\begin{array}{l}\text { A married person having sexual relations } \\
\text { with someone other than his/her partner } \\
\text { A person who has a regular partner they }\end{array}$ & $\begin{array}{l}\mathrm{M} \\
\mathrm{F} \\
\mathbf{M} \\
\mathbf{F}\end{array}$ & $\begin{array}{r}91 \cdot 3 \\
88 \cdot 2 \\
4 \cdot 7 \\
3 \cdot 8\end{array}$ & $\begin{array}{l}261 \\
244 \\
252 \\
240\end{array}$ & $\begin{array}{r}82 \cdot 4 \\
75 \cdot 6 \\
3 \cdot 9 \\
2 \cdot 1\end{array}$ & $\begin{array}{l}7271 \\
9103 \\
7196 \\
9164\end{array}$ & $\begin{array}{l}p<0.03 \\
p<0.03 \\
p<0.5 \\
p<0.2\end{array}$ \\
\hline $\begin{array}{l}\text { don't love having sexual relations with } \\
\text { someone other than his/her partner } \\
\text { One night stands } \\
\text { Sex between two men } \\
\text { Sex between two women } \\
\text { Abortion }\end{array}$ & $\begin{array}{l}M \\
F \\
M \\
F \\
M \\
F \\
M \\
F \\
M \\
F\end{array}$ & $\begin{array}{r}14 \cdot 3 \\
5 \cdot 9 \\
35 \cdot 5 \\
12 \cdot 1 \\
42 \cdot 4 \\
56 \cdot 3 \\
45 \cdot 1 \\
55 \cdot 2 \\
36 \cdot 3 \\
37 \cdot 2\end{array}$ & $\begin{array}{l}251 \\
242 \\
249 \\
242 \\
248 \\
225 \\
245 \\
224 \\
247 \\
228\end{array}$ & $\begin{array}{r}18 \cdot 2 \\
12 \cdot 2 \\
24 \cdot 6 \\
6 \cdot 7 \\
23 \cdot 4 \\
31 \cdot 7 \\
26 \cdot 5 \\
31 \cdot 3 \\
25 \cdot 9 \\
20 \cdot 2\end{array}$ & $\begin{array}{l}7143 \\
9111 \\
7128 \\
9160 \\
7080 \\
8603 \\
7022 \\
8639 \\
6750 \\
8449\end{array}$ & $\begin{array}{l}p<0.5 \\
p<0.03 \\
p<0.01 \\
p<0.07 \\
p<0.001 \\
p<0.001 \\
p<0.001 \\
p<0.001 \\
p<0.001 \\
p<0.001\end{array}$ \\
\hline
\end{tabular}

*Significance of the relationship between attitudes and STD clinic attendance after allowing for the effect of age. 
shown in table 5. Non-attenders were significantly more likely to perceive themselves as "not at all at risk of AIDS".

Attenders had significantly more liberal attitudes towards homosexual partnerships, abortion and sex before marriage. Male attenders and non-attenders were equally intolerant of married people and those in stable relationships having sexual relations with someone other than their partner though female attenders were more intolerant than non-attenders. Male attenders, but not female attenders, were more tolerant than non-attenders of one night stands.

\section{Discussion}

This is the only study in Britain able to provide population-based estimates of the extent and pattern of STD clinic use. The study has highlighted the paucity of data routinely available on characteristics of STD clinic attenders and underlines the need for improved information and surveillance systems for the service.

With respect to the proportion of the population attending clinics, the findings indicate that clinics are used by a substantial minority and wide demographic spectrum of the population. There is evidence of increasing use by younger generations, since lifetime use was most common in those age 25-34 years. This is consistent with known sexual behaviour changes in the last 30 years, such as earlier age of first sexual intercourse, and increasing numbers of partners, as well as with increasing attendance figures and the establishment of expanding numbers of clinics since the 1960 s. $^{10}$ However, it may also indicate the increasing acceptability of clinics to the general public.

We have demonstrated much higher rates of STD clinic attendance in Inner London than elsewhere with more than 1 in 10 of the resident population age 16-59 attending in the last five years. These are the first residencebased data available. KC60 statistics, collected from STD clinics by the Department of Health record district of attendance, but not district of residence. This is an important finding for the purchasing of GUM services. There have been concerns among Inner London districts that the open-access services implied that central clinics were providing a large element of service for non-residents (particularly commuters). These data indicate that the known higher rates of attendance in Inner London reflect considerably increased consulting rates by residents. In turn, evidence from the survey ${ }^{11}$ indicate that higher rates of risk behaviour occur in Inner London as compared with Outer London and all other regions, thus suggesting that the higher consulting rates in London reflect a genuinely increased need for services and not simply greater demand or availability. This conclusion is reinforced by the lack of association between geographical region and clinic attendance in the multivariate model (table 3).

The precision of our estimates depends on the accuracy of the self-reports provided by respondents and on sample representativeness. The sample was broadly representative of the demographic composition of the population, although the design excluded the homeless and populations in institutions. There is no direct method of assessing the number of STD clinic attenders in 1991 from KC60 data, and there have been no recent national surveys to assess the relationship between attendances and attenders. In 1978, Belsey and Adler ${ }^{2}$ carried out a survey of a representative sample of STD clinic attenders in England and Wales. The ratio of attendances to attenders was $1 \cdot 3: 1$ although there was variation by region and sexual orientation. From this they estimated that 332000 people attended clinics in England and Wales in 1978. The equivalent estimate from our data is 261000 in the last year and just under 900000 in the last five years. The number of attendances recorded from official statistics ${ }^{3}$ has increased since the 1970 s, though not necessarily the number of attenders. Taken together, however, these data suggest that there may have been some under-reporting of clinic attendance in the survey. This could result in under-estimation of the proportion of the population attending and some misclassification error between attenders and non-attenders. If this is the case, the effect on the analysis is likely to be to underestimate both the magnitude of the relationship between sexual behaviour and clinic attendance and to under-estimate the proportion of the population with risk markers who attend clinics.

Taking into account these methodological caveats, attenders differed very markedly in their sexual behaviour from non-attenders. In multivariate analysis which attempted to control for confounding between variables, the sexual behaviour variables had the strongest relationship with the probability of attendance. The magnitude of the association with variables such as abortion, paying for sex and anal sex, identified in the bivariate analysis were attenuated in the multivariate analysis. Although remaining independently associated in the final model, the magnitude of their effects is smaller, suggesting that these variables operate as markers for larger numbers of partners. While attenders were much more likely to have paid for sex than non-attenders, these contacts may not necessarily imply a greatly increased likelihood of STD transmission over that of other types of partnership. Ward et $a l^{12}$ have shown that rates of condom use between prostitutes and clients in this country are very high, and though female prostitutes may have a relatively high prevalence of STD, these may be acquired through unprotected intercourse with non-paying partners rather than from clients.

While attenders and non-attenders differed considerably in their behaviour, they varied to a much lesser degree in their attitudes. While attenders tended to have more liberal attitudes towards homosexuality and abortion, they were strikingly similar to non-attenders in their attitudes to adultery and unfaithfulness- 
less than $5 \%$ of respondents felt that adultery was rarely or never wrong, while clinic attenders were only marginally more tolerant of one night stands. This underlines the complex relationship between attitudes and behaviour, although it may also be that the type of concurrent relationships censured by respondents were those precipitating STD clinic attendance and thus influenced their attitudes.

STD clinics appear to be relatively efficient at specifically attracting into the clinics those with high-risk lifestyles who might benefit from STD screening, treatment and prevention. More than $60 \%$ of attenders reported one or more risk markers as compared with only $14 \%$ of the non-attending populations. This finding vindicates the continuation of an open-access service to STD clinics without GP referral, since it indicates that individuals are able to appropriately use clinics on the basis of their own assessment of personal risk. We were not able, however, to assess from our data in this general behaviour survey the reasons for attending, the proportion of attenders who were symptomatic or the proportion with diagnosed STD.

At a population level, relatively high proportions of those with particularly high risk lifestyles attend clinics $(26.7 \%$ of men with homosexual partners and $18.7 \%$ of men paying for sex in the last year). Of course, the converse of this is that there remains a substantial proportion of the population who report highrisk behaviours and do not attend clinics. This population numerically considerably outweighs the number attending clinics. These individuals may not require screening or treatment and may be more likely to be uninfected and symptom-free than attenders. Community studies suggest relatively low rates of undiagnosed syphilis and gonorrhoea in the community, though much herpes virus infection goes undetected, ${ }^{13}$ and rates of asymptomatic genital chlamydia in selected female populations is in the order of $7-12 \%$ have been reported. ${ }^{14}$

These findings suggest that the high concentration of high-risk individuals attending clinics makes them an important focus for sexual health promotion, but that community programmes are also important for reaching non-attenders. The general improvement in the standard of accommodation for GUM services since the publication of the Monks Report $^{15}$ which highlighted the poor condition of many clinics may attract a higher proportion of those at risk into clinics. The generally increased concerns of sexual health as a public health issue, combined with increased awareness of the need to improve integration of sexual health services may in future increase demand for services.

The fieldwork for the survey was carried out by Social \& Community Planning Research. Over 500 of SCPR's fieldforce of interviewers carried out the interviews. The survey was funded by the Wellcome Trust.

1 Catchpole M. Sexually transmitted diseases in England and Wales: 1981-1990. CDR 1992;2:R1-R12.

2 Belsey EM, Adler MW. Study of STD clinic attenders in England and Wales 1978: 1 . Patients versus cases. $\operatorname{Br} \mathcal{F}$ Venereal Dis 1981;57:285-9.

3 Department of Health. New cases seen at NHS Genito Urinary Medicine clinics in England. Years 1988/89 and 1989/90. Summary information from form KC60. London: Department of Health SM12B, 1991.

4 HM Government. The Health of the Nation. A strategy for health in England. London: HMSO, 1991.

5 Johnson AM, Wadsworth J, Wellings K, Field J. Sexual Attitudes and Lifestyles. Oxford: Blackwell Scientific Press, 1994.

6 Wellings K, Field J, Johnson AM, Wadsworth J. Sexual Behaviour in Britain. Penguin, 1994.

7 Evans BA, McCormack SM, Bond RA, MacRae KD Trends in sexual behaviour and HIV testing among women presenting at a genitourinary medicine clinic durwomen presenting at a genitourinary medicine clinic dur
ing the advent of AIDS. Genitourin Med 1991;67:194-8.

8 Johnson AM, Wadsworth J, Wellings K, Bradshaw S, Field J. Sexual lifestyles and HIV risk. Nature 1992;360 410-12.

9 Wadsworth J, Field J, Johnson AM, Bradshaw S, Wellings K. Methodology of the National Survey of Sexual Attitudes and Lifestyles. $\mathcal{F} R$ Statist Soc 1993;156: 407-21.

10 Adler MW. Sexually transmitted disease. In: Miller DL, Farmer RDT, eds. Epidemiology of Diseases. Oxford: Blackwell Scientific Publications, Oxford, 1982

11 Wadsworth J, Hickman M, Johnson AM, Wellings K, Field $\mathrm{J}$. Geographic variation in sexual behaviour in Britainimplications for sexually transmitted disease epidemiolimplications for sexually transmitted disease epidemiol-

12 Ward H, Day S, Mezzone J. Prostitution and HIV risk: Ward H, Day S, Mezzone J. Prostitution and HIV
prostitute women in London. BMf 1993;307:356-8.

13 Cowan FM, Johnson AM, Ashley R, Corey L, Mindel A. Antibody to herpes simplex virus type 2 as serological marker of sexual lifestyle in populations. BMF 1994 309:1325-9.

14 Taylor-Robinson D. Chlamydia trachomatis and sexually transmitted disease. BMf 1994;308:150-1.

15 Anonymous Working Group to examine workloads in genitourinary medicine clinics Report. London: $\mathrm{DoH}, 1988$ (Chairman: A Monk). 1988; (Abstract). 